\title{
Small herbivores and abiotic heterogeneity promote trait variation of a saltmarsh plant in local communities
}

\author{
Qingqing Chen ${ }^{\text {Corresp., } 1}$, Christian Smit ${ }^{1}$, Ido Pen $^{1}$, Han Olff ${ }^{1}$ \\ ${ }^{1}$ Groningen Institute for Evolutionary Life Sciences (GELIFES), University of Groningen, Groningen, The Netherlands \\ Corresponding Author: Qingqing Chen \\ Email address: chqq365@hotmail.com
}

Intraspecific trait variation (ITV) enables plants to respond to global changes. However, causes for ITV, especially from biotic components such as herbivory, are not well understood. We explored whether small vertebrate herbivores (hares and geese) impact ITV of a dominant clonal grass (Elytrigia atherica) in local communities. Moreover, we looked at the relative importance of their direct (e.g. selective grazing) and indirect effects (altering genotypic richness/diversity and abiotic environment) on ITV. We used exclosures at two successional stages in a Dutch saltmarsh, where grazing pressure at the early successional stage was ca. 1.5 times higher than that of the intermediate successional stage. We measured key functional traits of $E$. atherica including height, aboveground biomass, flowering (flower or not), specific leaf area, and leaf dry matter content in local communities ( $1 \mathrm{~m} \times 1 \mathrm{~m}$ plots) inside and outside the exclosures. We determined genotypic richness and diversity of each plant using molecular markers. We further measured abiotic variations in topography and clay thickness (a proxy for soil total nitrogen). Structural equation models revealed that small herbivores significantly promoted ITV in height and flowering at the early successional stage, while they marginally promoted ITV in height at the intermediate successional stage. Moreover, the direct effects of herbivores played a major role in promoting ITV. Small herbivores decreased genotypic diversity at the intermediate successional stage, but genotypic richness and diversity did not impact ITV. Small herbivores did not alter topographic variation and variation in clay thickness, but these variations increased ITV in all traits at the early successional stage. Small herbivores may not only impact trait means in plants as studies have shown but also their ITV. 
1 Small herbivores and abiotic heterogeneity promote trait variation of a saltmarsh plant in

2 local communities

3 running title: small herbivores and trait variation

4 Qingqing Chen ${ }^{1 *}$, Christian $\mathrm{Smit}^{1}$, Ido Pen ${ }^{1,}$ Han Olff ${ }^{1}$

5 Affiliations:

61 Groningen Institute for Evolutionary Life Sciences (GELIFES), University of Groningen,

7 Nijenborgh 7, 9747 AG Groningen, The Netherlands.

8 *Correspondence to Qingqing Chen (chqq365@gmail.com); ORCID: 0000000319573848

9 


\section{Abstract}

11 Intraspecific trait variation (ITV) enables plants to respond to global changes. However, causes

12 for ITV, especially from biotic components such as herbivory, are not well understood. We

13 explored whether small vertebrate herbivores (hares and geese) impact ITV of a dominant clonal

14 grass (Elytrigia atherica) in local communities. Moreover, we looked at the relative importance

15 of their direct (e.g. selective grazing) and indirect effects (altering genotypic richness/diversity

16 and abiotic environment) on ITV. We used exclosures at two successional stages in a Dutch

17 saltmarsh, where grazing pressure at the early successional stage was ca. 1.5 times higher than

18 that of the intermediate successional stage. We measured key functional traits of E. atherica

19 including height, aboveground biomass, flowering (flower or not), specific leaf area, and leaf dry

20 matter content in local communities $(1 \mathrm{~m} \times 1 \mathrm{~m}$ plots $)$ inside and outside the exclosures. We

21 determined genotypic richness and diversity of each plant using molecular markers. We further

22 measured abiotic variations in topography and clay thickness (a proxy for soil total nitrogen).

23 Structural equation models revealed that small herbivores significantly promoted ITV in height

24 and flowering at the early successional stage, while they marginally promoted ITV in height at

25 the intermediate successional stage. Moreover, the direct effects of herbivores played a major

26 role in promoting ITV. Small herbivores decreased genotypic diversity at the intermediate

27 successional stage, but genotypic richness and diversity did not impact ITV. Small herbivores

28 did not alter topographic variation and variation in clay thickness, but these variations increased

29 ITV in all traits at the early successional stage. Small herbivores may not only impact trait means

30 in plants as studies have shown but also their ITV.

31 Keywords: trait variation; plant-herbivore interaction; grazing; abiotic; genetic diversity;

32 saltmarsh 


\section{Introduction}

34 Studies show that intraspecific trait variation (i.e. variability in traits of conspecific individuals;

35 hereafter ITV) can enable plant species to respond to global changes (Westerband, Funk \&

36 Barton, 2021), impact community composition and structure (Whitlock, Grime \& Burke, 2010),

37 and govern ecosystem processes (Boege \& Dirzo, 2004; Crutsinger et al., 2006; Crutsinger,

38 Souza \& Sanders, 2008; Lecerf \& Chauvet, 2008). The importance of ITV has been increasingly

39 realized over the years (Violle et al., 2012; Siefert et al., 2015; Funk et al., 2017; Westneat et al.,

40 2019; Westerband, Funk \& Barton, 2021), therefore, exploring the causes for ITV is of prime

41 importance, particularly under the current rapid global changes (Westerband, Funk \& Barton,

42 2021). Several components including genotypic richness/diversity and phenotypic plasticity

43 triggered by biotic and abiotic environments can drive ITV (Valladares, Gianoli \& Gomez,

44 2007). However, biotic components, particularly herbivory, received much less attention than

45 genotypic richness/diversity and abiotic environments (Valladares, Gianoli \& Gomez, 2007).

47 Whilst herbivores are one of the major drivers for plant trait differentiation globally (Díaz et al., 48 2007; He \& Silliman, 2016), the majority of the studies that document the effects of herbivores

49 on plant traits focus on trait means without considering ITV (e.g. Bullock et al., 2001; Louault et

50 al., 2005; Kahmen \& Poschlod, 2008). Limited studies suggest that herbivores may also impact

51 ITV (e.g. Jessen et al., 2020). However, these studies mainly focus on large herbivores. Large

52 and small herbivores are relative. Here we refer to small herbivores as vertebrate herbivores with

53 body mass ranging from 1 to $10 \mathrm{~kg}$ such as hares and geese. Small herbivores sometimes can

54 have stronger impacts on plant communities than large ones especially when their abundance is 
55 high (Olofsson et al., 2004). Additionally, small herbivores are usually more selective with

56 forage plants (Olff \& Ritchie, 1998). Therefore, small herbivores may also impact ITV, however,

57 we currently lack empirical evidence. As small herbivore populations are changing dramatically

58 due to human actions (Smith, Jennings \& Harris, 2005; Menu, Gauthier \& Reed, 2002), it is

59 important to understand whether and how small herbivores impact ITV.

60 Small herbivores may impact ITV via multiple non-exclusive processes. First, small herbivores

61 can promote ITV through selective grazing. Studies show that large herbivores generally prefer

62 young plants that are often more nutritious (e.g. higher protein and lower lignin and cellulose)

63 (Augustine \& McNaughton, 1998). Thus, larger herbivores decrease plant height by grazing

64 them down (Díaz et al., 2007; Evju et al., 2009). Similarly, small herbivores may prefer young

65 plants and decrease plant height, but because small herbivores consume less and they are more

66 selective with forage plants, some young plants may escape from small herbivores via

67 association with unpalatable species (Van Der Wal et al., 2000; Kuijper \& Bakker, 2008). Thus,

68 small herbivores may promote variation in plant height. Second, small herbivores may impact

69 ITV indirectly through altering genotypic richness and diversity. Increased genotypic richness

70 and diversity can increase ITV (Evans et al., 2016). Studies looking at the effects of large

71 herbivores on genotypic diversity show that large herbivores can increase genotypic diversity by

72 promoting seed transportation (Rico \& Wagner, 2016) or decrease it by promoting clonal growth

73 (Kleijn \& Steinger, 2002). Small herbivores can have similar effects to large ones on many

74 processes such as seed dispersal (Bakker \& Olff, 2003). Therefore, small herbivores can either

75 increase or decrease genotypic richness and diversity. Third, small herbivores may promote ITV

76 indirectly through altering abiotic heterogeneity (e.g. topographic variation and variation in soil

77 nutrients) via grazing the vegetation at particular spatial scales, trampling, and localized 
78 deposition of droppings (Adler, Raff \& Lauenroth, 2001). Abiotic heterogeneity usually

79 promotes ITV (Westerband, Funk \& Barton, 2021). However, whether small herbivores impact

80 ITV via these processes and the relative importance of them in shaping ITV remains

81 underexplored.

82

83 To test these hypotheses, we used long-term (22-year) exclosure experiment at the early and intermediate successional stages of a Dutch saltmarsh. In the eastern part of the saltmarsh of the island of Schiermonnikoog, hares and geese are the abundant herbivores while large herbivores are absent (Kuijper \& Bakker, 2005; Schrama et al., 2015; Chen et al., 2019). A well-calibrated successional gradient is present here (Olff et al., 1997). Hares and geese are more abundant at the early successional stages but their abundance decreases at intermediate and late successional stages due to less preferred late successional plants such as Elytrigia atherica (synonym Elymus athericus) increase in dominance (Kuijper \& Bakker, 2005; Schrama et al., 2015; Chen et al., 2019). Elytrigia atherica mainly reproduces clonally, but sexual reproduction may occur occasionally via windows of opportunity and their seeds are mainly dispersed by tidal water, thus genotypic richness is high in this grass (Bockelmann et al., 2003; Change et al., 2005; Chen, 2020). Topographic variation and variation in clay thickness are important factors for the growth and expansion of E. atherica in saltmarshes (Olff et al., 1997; Nolte et al., 2019). Thus, the longterm exclosure experiment along the successional gradient in this saltmarsh provides ideal conditions to look at the effects of small herbivores on ITV in plants. 
99 In this study, we look at the effects of hares and geese on ITV of E. atherica in local

100 communities $(1 \mathrm{~m} \times 1 \mathrm{~m}$ plots $)$. This is because ITV is usually strongly driven by processes

101 operating at small spatial scales (Westerband, Funk \& Barton, 2021). We measured key

102 functional traits of this dominant grass including height, aboveground biomass, flowering

103 (flower or not), specific leaf area, and leaf dry matter content within local communities inside

104 and outside the exclosures. Using structural equation models, we test whether hares and geese

105 impact ITV of E. atherica, and the relative importance of their direct effects (e.g. selective

106 grazing) and indirect effects (via altering genotypic richness/diversity and abiotic variables) on

107 ITV. We expect that hares and geese would increase ITV in all traits measured and their effects

108 would be more apparent at the early successional stage (relative to the intermediate one) where

109 grazing pressure was higher. Although adult plants of E. atherica are less preferred, hares and

110 geese considerably graze on its seedling/young plants (Kuijper, Nijhoff \& Bakker, 2004;

111 Fokkema et al., 2016). However, short seedlings/young plants may escape from grazing by

112 associating with non-preferred plants such as Artemisia maritima. Hares and geese may increase

113 topographic variation via trampling (Wijnen, Wal \& Bakker, 1999; Elschot et al., 2015), they

114 may also impact sediment accumulation (measured by clay thickness) by trampling and altering

115 vegetation structure (Boorman, Garbutt \& Barratt, 1998). However, because hares and geese play

116 a less important role than tidal water in seed dispersal (Chang et al., 2005), it is unlikely that they

117 can increase genotypic richness and diversity by dispersing seeds. Instead, hares and geese may

118 decrease genotypic richness and diversity by promoting clonal spread of E. atherica (Van Der

119 Graaf, Stahl \& Bakker, 2005). Therefore, we also expect that hares and geese may increase ITV

120 through selective grazing and promoting topographic variation and variation in clay thickness but

121 may decrease ITV by decreasing genotypic richness and diversity. 


\section{Materials and methods}

\section{Study site}

125 A natural successional gradient is present in the back-barrier saltmarsh of the island of

126 Schiermonnikoog $\left(53^{\circ} 30^{\prime} \mathrm{N}, 6^{\circ} 10^{\prime} \mathrm{E}\right)$, the Netherlands. Because this island expands eastward,

127 thus the eastern part of the island is younger relative to the western part (Olff et al., 1997). The

128 western part of the saltmarsh is enclosed for cattle grazing, while the eastern part of it is grazed

129 by wild small herbivores such as spring staging geese, year-round present hares and rabbits.

130 Hares and geese are the most abundant herbivores (Van de Koppel et al., 1996; Van Der Wal,

131 Kunst \& Drent, 1998; Wal et al., 2000; Kuijper \& Bakker, 2005; Schrama et al., 2015). Rabbits

132 are very rare. Kuijper and Bakker (2005) found that biomass removed by rabbits in 2000 was

$1336.33 \%$ and $0.16 \%$ of the total biomass removed by small herbivores at the early and intermediate

134 successional stage, respectively.

136 We used long-term hare and goose exclosures that were initiated in 1994 (details in Chen et al.,

137 2019). We selected exclosures located at the early and intermediate successional stages, which

138 are approximately $2.5 \mathrm{~km}$ apart (Fig. 1A). Vegetation succession has undergone around 30 and

13960 years at the early and intermediate successional stage, respectively. Age of the vegetation

140 succession was counted from the year of vegetation establishment to 2016. The year of

141 vegetation establishment was determined by checking aerial photographs (Olff et al., 1997).

142 Grazing pressure from hares and geese was ca. 1.5 times higher at the early successional stage 
143 than the intermediate successional stage based on year-round dropping count in 2000 and 2016

144 (see Table S1 for more details; Kuijper \& Bakker, 2005; Chen et al., 2019; Chen et al., 2019a).

146 Hare and goose exclosures (one per each successional stage) were located in a similar elevation

147 (early stage: $1.42 \pm 0.004$; intermediate stage: $1.44 \pm 0.004$; mean $\pm 1 \mathrm{se}$; $\mathrm{N}=24 ; \mathrm{m}+\mathrm{NAP}$; Normal

148 Amsterdam Water Level). Exclosures $(8 \mathrm{~m} \times 12 \mathrm{~m}$ and $6 \mathrm{~m} \times 8 \mathrm{~m}$ at the early and intermediate

149 successional stages) were made by chicken mesh (mesh width $25 \mathrm{~mm}$ ) supported by wooden

150 posts every $3.5 \mathrm{~m}$ to exclude hare grazing inside the exclosures. Exclosures were around $1 \mathrm{~m}$ in

151 height, ropes were suspended on top of the wooden posts to stop geese flying into the exclosures.

152 At the beginning of the exclosure experiment (1995), E. atherica rarely occurred $(<2.5 \%$;

153 percent cover) inside and outside the exclosures at these two stages. Vegetation composition

154 differed in the grazed areas and inside the exclosures in 2016 (Fig.1; also see Table S2 for

155 species composition for the three most abundant species). Specifically, Artemisia maritima was

156 the most dominant plant in the grazed area at these two stages, while E. atherica was the most

157 dominant plant inside the exclosures.

Experimental design

160 To make our results spatially comparable, we sampled within ca. $6 \mathrm{~m} \times 8 \mathrm{~m}$ inside and outside

161 the exclosures at both successional stages in June 2017. We chose this size because this is the

162 largest area we can sample inside the exclosures at the intermediate successional stage. The

163 distance between the area and the exclosure measured ca. $80 \mathrm{~m}$. We randomly set up 7 plots $(1 \mathrm{~m}$

$164 \times 1 \mathrm{~m}$ ) inside these two grazed areas and exclosures (Fig. 1). The distance between these plots 
165 ranged from $0.5 \mathrm{~m}$ to $9 \mathrm{~m}$. We divided each plot into 25 grids $(0.2 \mathrm{~m} \times 0.2 \mathrm{~m})$. Within each grid,

166 we collected one individual stem of E. atherica (with roots), usually in the middle of the grid

167 (Fig. 1). Elytrigia atherica did not occur everywhere, particularly not in the grazed area, thus

168 sample size per plot varied from 9 to 25.

\section{Trait measurement}

171 We measured traits for individual stems of E. atherica in the field. We sampled individual stems

172 without obvious grazing marks. We cut individual stems at the ground level and measured

173 maximum height $(\mathrm{cm})$ from the base to the highest point. We measured the maximum leaf width

174 and length of the first fully grown leaf, usually the third leaf from the top. We also recorded

175 whether individual stems flowered or not. After these measurements, each stem was stored in a

176 paper bag, sealed, labeled, and then put in a self-sealing plastic bag to reduce water loss in

177 tissues. At the end of each day, samples were brought to the lab, we measured fresh biomass of

178 the individual stems and fully-grown leaves. We also measured their dried biomass (g) after

179 oven-dry $\left(70^{\circ} \mathrm{C}\right)$ to constant mass (ca. 3 days). We calculated specific leaf area $\left(\mathrm{mm}^{2} \mathrm{mg}^{-1}\right)$ as

180 (leaf width $\times$ leaf length) / dried leaf biomass. We calculated leaf dry matter content $\left(\mathrm{mg} \mathrm{g}^{-1}\right)$ as

181 dried leaf biomass / fresh leaf biomass. Specific leaf area and leaf dry matter content were not

182 measured in the standard way (Pérez-Harguindeguy et al., 2016), and caution should be taken

183 when comparing our data with other studies. Due to that reason, in the main text, we focus on

184 height, aboveground biomass, and flowering, we present the results for specific leaf area and leaf 185 dry matter content in the online supporting file. 


\section{Genotyping and genotype richness and diversity}

188 We used oven-dried leaf samples (ca. $2 \mathrm{mg}$ per individual stem) for DNA extraction. We first

189 shredded leaf samples into smaller pieces using tissuelyser. We then extracted DNA from each

190 leaf sample using the CTAB method (Doyle \& Doyle, 1987) and stored DNA samples at $-20^{\circ} \mathrm{C}$

191 before PCR. We amplified DNA using PCR with fluorescence-labeled primers. We used five

192 microsatellite markers (ECGA89, WMS6, WMS44, WMS2, and ECGA89) originally designed

193 for the other Poaceae species, Elymus caninus (Sun, Salomon \& Bothmer, 1998) and Triticum

194 aestivum (Röder et al., 1998). These five markers were used for genotyping E. atherica in this

195 system (Bockelmann et al., 2003; Chen 2020). The PCR products from primer ECGA89, WMS6,

196 and WMS44 were pooled together, while the PCR products from WMS2 and ECGA89 were

197 pooled together. Additionally, $1 \mu \mathrm{L} \mathrm{rROX}$ was added in each sample as the internal size standard

198 (Gene ScanTM-350 ROXTM, Applied Biosystem). We visualized the pooled PCR products

199 using the 3730 DNA analyzer and scored the microsatellite peak patterns (height $>100)$

200 manually using GeneMapper. In total, we successfully genotyped 579 individual stems of $E$.

201 atherica, but 2 were excluded for further analyses as some trait data measured in the field for

202 these samples were missing.

204 Abiotic variables

205 We measured clay thickness and topographic variation for each plot (3 replicates). We measured

206 clay thickness using a $2 \mathrm{~cm} \varnothing$ soil corer with tick marks as a proxy for soil total nitrogen (Olff et

207 al., 1997). Previous studies show that clay thickness is strongly positively correlated with soil

208 total nitrogen in this system (i.e. total nitrogen $(\mathrm{g})=186+43$ clay thickness $(\mathrm{cm}) ; \mathrm{r}=0.9$, 
$209 \mathrm{p}<0.0001$; Olff et al., 1997). Also, clay thickness is used as a proxy of soil fertility (e.g. Schrama

210 et al., 2017). We measured topography using Trimble R8 (precision for elevation ca. $1 \mathrm{~cm}$ ).

211

\section{Data analysis}

213

214 Calculating trait means, ITV, topographic variation, and variation in clay thickness

215 We calculated means for each trait by averaging trait values over $9-25$ individual stems in each

216 plot. We calculated ITV in each trait each plot as the standard deviation /mean. Topographic

217 variation and variation in clay thickness were calculated as standard deviation /mean (over 3

218 samples) of elevation and clay thickness, respectively.

219

220

Calculating genotypic richness, genotypic diversity, and genetic differentiation

221 To calculate genotype richness and diversity per plot, we first calculated pairwise genetic

222 distance using Dice dissimilarity from the R package ade4 (Dray \& Dufour, 2015) based on the

223 presence/absence matrix of 42 allele bands from those five markers. We then assigned genotypes

224 based on dice dissimilarity, using the function "assignClones" from the R package polysat

225 (Lindsay, Clark \& Clark, 2018). We calculated genotypic richness as the number of unique

226 genotypes detected divided by the number of individual stems genotyped for each plot.

227 Genotypic diversity - taking into account the abundance of different genotypes - was calculated

228 using the function "genotypeDiversity" with the index of "Shannon" from the package polysat

229 (Lindsay, Clark \& Clark, 2018). Because small herbivores may select for some particular

230 genotypes that are more resistant or tolerant to herbivore grazing (Kotanen \& Bergelson, 2000),

231 which may also impact traits. We explored genetic differentiation using principal coordinates 
232 analysis (PCoA) from the R package ade4 (Dray \& Dufour, 2015). We looked at genetic

233 differentiation at the treatment level, that is, grazed and ungrazed across plots at each

234 successional stage, result can be found in Fig. S1.

235

236

Effects of small herbivores on trait means and ITV

237 Although our focus is on ITV, to compare whether the effects of small herbivores on ITV are

238 stronger than trait means, we also looked at the effects of small herbivores on trait means. We

239 use analysis of variance, function " $1 \mathrm{~m}$ ", to look at the effects of small herbivores on means and

240 ITV of each trait at the early and intermediate successional stage, separately. We checked model

241 assumptions by visually inspecting residual plots for homogeneity and quantile-quantile plots for

242 normality. In all cases, models fitted the data reasonably well.

244 Direct and indirect effects of small herbivores on ITV

245 We estimated the direct, indirect effects through altering genotypic richness and diversity,

246 indirect effects through altering abiotic variables, and total effects (sum of direct and indirect

247 effects) of small herbivores on ITV. We estimated these effects in each trait at each successional

248 stage based on the standardized path coefficients using structural equation models from the R

249 package "lavaan” (Rosseel, 2012). Grazing (0: ungrazed, 1: grazed), genotypic richness,

250 genotypic diversity, topographic variation, and variation in clay thickness were included in the

251 models. Note that genotypic diversity was not included for ITV at the early successional stage, as

252 it was significantly correlated with genotypic richness (variance inflation factor $>4$ ). See online

253 supporting text for an example of a structural equation model for ITV in height at the

254 intermediate successional stage and calculation of the direct and indirect effects. Effects are 
255 significant when $p \leq 0.05$, while marginally significant when $p>0.05$ and $\mathrm{p}<0.1$. Data analysis

256 was performed in R3.5.3 (R Core Team 2020).

257

258 Results

259

Effects of small herbivores on trait means and ITV

260

At the early successional stage, small herbivores significantly decreased means in height,

261

aboveground biomass, and flowering of E. atherica. Also, small herbivores significantly

262 increased ITV in flowering and marginally increased ITV in height, but had no effects on ITV in

263 aboveground biomass. At the intermediate successional stage, small herbivores significantly

264 decreased means in height, aboveground biomass, and flowering. However, small herbivores had

265 no effects on ITV in all traits (Fig. 2; see Table S3 for test statistics). Small herbivores did not

266 impact mean and ITV in specific leaf area and leaf dry matter content at both successional stages

267 except that small herbivores decreased mean in specific leaf area at the intermediate successional 268 stage (Table S3).

269

270

Direct and indirect effects of small herbivores on ITV

271 The structural equation model reveals that overall (summing up the direct and indirect effects),

272 small herbivores tended to promote ITV in height and flowering, but not in other traits at the

273 early successional stage. Overall, small herbivores tended to promote ITV in height, but not in

274 other traits at the intermediate stage. Moreover, these positive overall effects of small herbivores

275 on ITV in height and flowering were mainly attributable to their direct effects. Although the

276 overall effects of small herbivores on ITV in aboveground biomass and specific leaf area were

277 not significant, small herbivores also directly significantly impacted ITV in these two traits at the 
278 early successional stage (Fig 3; Fig. S2). See Table 1 for the standardized path coefficient

279 estimated from SEM for the direct, indirect, and total effects of small herbivores on ITV.

280

281 At the early successional stage, small herbivores did not have significant effects on genotypic

282 richness and diversity, but genotypic richness decreased ITV in flowering. At the intermediate

283 successional stage, small herbivores did not have significant effects on genotypic richness, but

284 significantly reduced genotypic diversity. However, genotypic richness and diversity did not

285 impact ITV in any traits at the intermediate successional stages (Fig. 3; Fig. S2).

286

287 Small herbivores did not impact topographic variation and variation in clay thickness at both 288 successional stages. However, these variations significantly increased ITV in all traits at the 289 early successional stage except that the effects of topographic variation on ITV in flowering were 290 not significant. The effects of these variations on ITV were less apparent at the intermediate 291 successional stage except that variation in clay thickness marginally decreased ITV in height 292 (Fig. 3; Fig. S2).

293

294 Discussion

295

296 In this study, using long-term exclosures, in combination with field observations and genetic 297 analyses, we explored ITV of a dominant clonal grass (Elytrigia atherica) and the direct and 298 indirect effects of small herbivores on ITV. We found that, at the early successional stage, small 299 herbivores promoted ITV in height and flowering of this grass. At the intermediate successional 300 stage, small herbivores marginally promoted ITV in height. Moreover, small herbivores 
301 promoted ITV mainly through direct effects (e.g. selective grazing) but not through altering

302 genotypic richness/diversity or topographic variation and variation in clay thickness.

303

304

Effects of small herbivores on trait means and ITV

305 Our results suggest that small herbivores could impact both means and variations in key

306 functional traits of E. atherica, but their effects differed in different traits. At the early

307 successional stage, we found that small herbivores significantly decreased means in three traits

308 measured (height, aboveground biomass, and flowering) and they significantly promoted ITV in

309 two traits (height and flowering). At the intermediate successional stage, small herbivores

310 significantly decreased means in four traits (height, aboveground biomass, flowering, and

311 specific leaf area) and they marginally promoted ITV in one trait (height; Fig. 2; Fig. S2). This

312 suggests that trait means and variations may be driven by different processes. Moreover, we only

313 observed ITV in height and flowering may be because these two traits have higher plasticity than

314 other traits, and traits with a higher level of plasticity also show higher ITV (Givnish, 2002).

315 Furthermore, small herbivores had similar effects on trait means at both successional stages, but

316 had stronger impacts on ITV at the early successional stage. This may be because the effects of

317 small herbivores on trait means and variations were mediated by community composition in the

318 field. At the early successional stage, the preferred plant, F. rubra, was more abundant in the

319 grazed area (ca. 3 times relative to that of the intermediate successional stage), thus small

320 herbivores (although more abundant) may graze more on F. rubra rather than E. atherica. At the

321 intermediate successional stage, the abundance of $F$. rubra deceased, while the abundance of $E$.

322 atherica increased in the grazed area (ca. 5 times relative to that of the early successional stage), 
323 thus small herbivores (less abundant) may also substantially grazed on less preferred E. atherica.

324 Therefore, overall, the effects of small herbivores on trait means were similar at these two stages.

325 Meanwhile, non-preferred species (A. maritima) was more abundant in the grazed area at the

326 early successional stage (ca. 2 times relative to that of the intermediate successional stage; see

327 Table S2 for detailed percent cover of these species). It may facilitate young E. atherica escape

328 from herbivore grazing. Therefore, ITV was more apparent at the early successional stage than

329 the intermediate one. Previous studies in this system have shown that hares and geese are the

330 important drivers for plant community composition and structure along this successional gradient

331 (Olff et al., 1997; Kuijper \& Bakker, 2005; Chen et al., 2019). Here, extending the current

332 knowledge, we show that small herbivores may also impact trait means and variations, which in

333 turn could impact community composition and structure (Whitlock, Grime \& Burke, 2010).

335 Direct and indirect effects of small herbivores on ITV

336 As we hypothesized, the direct effects of small herbivores through selective grazing increased

337 ITV. This is not only true for height and flowering but also for aboveground biomass and

338 specific leaf area, despite the overall effects of small herbivores on aboveground biomass and

339 specific leaf area were not significant. As explained in the previous paragraph, the direct effects

340 of small herbivores may be mediated by community composition especially the proportion of

341 preferred and non-preferred plants. Herz et al. (2017) found that local neighborhood diversity

342 can explain a large amount of ITV in German meadows and pastures, possibly through increased

343 plant-plant interactions (e.g. competition). In this study, plant diversity was higher in the grazed

344 than the ungrazed plots at both successional stages after 22-year grazing (Table S2). Thus, higher 
345 plant diversity may also contribute to increased ITV in height under grazing at both successional

346 stages. Future studies/experiments looking at the effects of herbivores on ITV in plant

347 communities with the same composition are needed to fully separate the effects of selective

348 grazing from the effects of neighboring plants.

350 We found that small herbivores did not impact genotype richness and diversity of E. atherica at

351 the early successional stage but decreased genotypic diversity at the intermediate successional

352 stage. A previous study in the west part of this saltmarsh found that cattle grazing does not

353 impact genotype richness and diversity of this grass, but cattle grazing alters its morphological

354 traits in the field such as decreasing height and leaf width (Veeneklaas et al., 2011). Here, we

355 found that genotypic richness and diversity generally had no significant effects on ITV.

356 Microsatellite markers are commonly used in studying plant genetics (Jarne \& Lagoda, 1996;

357 Vieira et al., 2016), but because they are selectively neutral, they may not control gene

358 expression for the traits measured here. More generally speaking, the genetic basis of most traits

359 in many wild plants is unknown. Thus, it is difficult to know in advance which genes or genomic

360 regions to consider, which further hinders inferring a causal relationship between genetic

361 variation and phenotypic variation (Merilä \& Hendry, 2014). A low correlation between

362 variation in morphological traits and DNA markers was also reported before (Kolliker et al.,

363 1998). Additionally, we found genetic differentiation of E. atherica in the grazed and ungrazed

364 areas at the early successional stage, but not at the intermediate successional stage (Fig. S1),

365 however, more data (presumably from more exclosures) are needed to consolidate this result.

366 Thus, the observed trait changes (at both successional stages) may not be associated with genetic

367 changes in E. atherica. 
369 In contrast, we found no effects of small herbivores on topographic variation and variation in

370 clay thickness within plots. These abiotic variations may be primarily induced by flooding and

371 inundation, which may overrule the effects of small herbivores in salt marshes. However,

372 variations in these two abiotic variables had substantial positive impacts on ITV particularly at

373 the early successional stage. Abiotic environment may be more heterogenous at the early

374 successional stage because this stage has more frequent sediment deposition than the

375 intermediate successional stage (Schrama, Berg \& Olff, 2012). A previous study conducted in

376 the western part of this saltmarsh also found that topographic variation at the small spatial scales

$377\left(0.1 \mathrm{~m}^{2}\right.$ and $\left.10 \mathrm{~m}^{2}\right)$ is positively correlated with species richness and cattle grazing additionally

378 increased species richness (Ruifrok et al., 2014). Thus, abiotic variations, even at very small

379 spatial scales, may play an important role in promoting ITV and altering other plant community 380 properties.

381

382

\section{Long-term exclosures}

383 Although we used 22-year old herbivore exclosures, our data cannot answer whether duration of

384 herbivore grazing impacts ITV, as we only collected data for one year. To our knowledge, no

385 studies have compared the effects of short- and long-term grazing on ITV. Didiano et al. (2014)

386 found that tolerance to rabbit grazing decreased as the age of the exclosures increased in $F$.

387 rubra, the most abundant plant in Silwood Park, England. Therefore, grazing duration may also 388 impact ITV. 


\section{Conclusion}

391 Our results suggest that small herbivores may not only impact means but also ITV in some key

392 functional traits of a dominant grass (E.atherica). Additionally, small herbivores impacted ITV

393 mainly through selective grazing but not through altering genotypic richness/diversity and

394 abiotic variations. However, topographic variation and variation in clay thickness may contribute

395 to ITV. Small herbivore populations are changing rapidly due to human actions. For instance,

396 populations of European brown hares have declined dramatically due to land-use changes

397 (Smith, Jennings \& Harris, 2005), while populations of geese are rapidly increasing globally

398 (Menu, Gauthier \& Reed, 2002). These changes in small herbivore populations could thus impact

399 their effects on ITV in plant species, which may have consequences for plants to respond to

400 increasing environmental changes.

Declarations

403

404 Funding: Not applicable

405 Conflicts of interest/Competing interests: The authors declare no conflict of interest.

406 Availability of data and material (data transparency): Data can be found

407 https://figshare.com/s/d7e2cee03c89cf0a9d6a. Date will be made public once the manuscript is 408 accepted. Figures are not copyrighted. 
409 Authors' contributions: QC conceived and designed the experiments, performed the

410 experiments, analyzed the data, and wrote the manuscript. All authors contributed to revisions

411 and gave final approval for publication.

412

413 Acknowledgments

414 We thank Iris Bontekoe, Erica Zuidersma for helping collect samples in the field. We thank

415 Marco van der Velde, Jan Veldsink, and Yvonne Verkuil for their help with genotyping in the

416 lab. We thank J. F. Scheepens for his constructive comments on the earlier versions of this

417 manuscript. We thank Juan Alberti and Oliver Carroll for their constructive suggestions for

418 improving the structure and readability of this manuscript. We thank three anonymous reviewers

419 and the associate editor for their constructive comments and suggestions. We thank

420 Natuurmonumenten for offering us the opportunity to work in the saltmarsh of the island of

421 Schiermonnikoog. QC is funded by CSC (China Scholarship Council).

\section{References}

423 Adler P, Raff D, Lauenroth W. 2001. The effect of grazing on the spatial heterogeneity of

424 vegetation. Oecologia 128:465-479. DOI: 10.1007/s004420100737.

425 Augustine DJ, McNaughton SJ. 1998. Ungulate Effects on the Functional Species Composition

426 of Plant Communities : Herbivore Selectivity and Plant Tolerance. The Journal of Wildlife

427 Management 62:1165-1183.

428 Bakker ES, Olff H. 2003. Impact of different-sized herbivores on recruitment opportunities for 
subordinate herbs in grasslands. Journal of Vegetation Science 14:465-474. DOI:

430 10.1658/1100-9233(2003)014[0465:IODHOR]2.0.CO;2.

431 Bockelmann AC, Reusch TBH, Bijlsma R, Bakker JP. 2003. Habitat differentiation vs. isolation432 by-distance: the genetic population structure of Elymus athericus in European salt marshes. 433 Molecular ecology 12:505-15. DOI: 10.1046/j.1365-294X.2003.01706.x.

434

435

436

437

438

439

440

441

442
Boege K, Dirzo R. 2004. Intraspecific variation in growth, defense and herbivory in Dialium guianense (Caesalpiniaceae) mediated by edaphic heterogeneity. Plant Ecology 175:59-69. DOI: 10.1023/B:VEGE.0000048092.82296.9a.

Boorman LA, Garbutt A, Barratt D. 1998. The role of vegetation in determining patterns of the accretion of salt marsh sediment. Geological Society, London, Special Publications 139: 389-399. https://doi.org/10.1144/GSL.SP.1998.139.01.29

Bullock JM, Franklin J, Stevenson MJ, Silvertown J, Sarah J, Gregory SJ, Tofts R. 2001. A Plant Trait Analysis of Responses to Grazing in a Long-Term Experiment. Journal of Applied Ecology 38:253-267.

Chang ER, Zozaya EL, Kuijper DPJ, Bakker JP. 2005. Seed dispersal by small herbivores and tidal water: Are they important filters in the assembly of salt-marsh communities? Functional Ecology 19:665-673. DOI: 10.1111/j.1365-2435.2005.01011.x.

Chen Q. 2020. Low-marsh ecotypes of a dominant plant may not be better adapted to increased sea level. Flora 273:151722. DOI: 10.1016/j.flora.2020.151722.

Chen Q, Howison RA, Bakker JP, Alberti J, Kuijper DPJ, Olff H, Smit C. 2019. Small herbivores slow down species loss up to 22 years but only at early successional stage. 

Journal of Ecology 107:2688-2696. DOI: 10.1111/1365-2745.13236.

451 Chen Q, Howison RA, Bakker JP, Alberti J, Kuijper DPJ, Olff H, Smit C. 2019a. Data from:

452 Small herbivores slow down species loss up to 22 years but only at early successional stage. 453 Dryad. http://dx.doi.org/10.5061/DRYAD.KR6409Q

454 Crutsinger GM, Collins MD, Fordyce JA, Gompert Z, Nice CC, Sanders NJ. 2006. Plant 455 Genotypic Diversity Predicts Community Structure and Governs an Ecosystem Process. $456 \quad$ Nature 313:966-968.

457 Crutsinger GM, Souza L, Sanders NJ. 2008. Intraspecific diversity and dominant genotypes 458 resist plant invasions. Ecology Letters 11:16-23. DOI: 10.1111/j.1461-0248.2007.01118.x.

459 Díaz S, Lavorel S, McIntyre S, Falczuk V, Casanoves F, Milchunas DG, Skarpe C, Rusch G, 460 Sternberg M, Noy-Meir I, Landsberg J, Zhang W, Clark H, Campbell BD. 2007. Plant trait 461 responses to grazing - A global synthesis. Global Change Biology 13:313-341. DOI: 10.1111/j.1365-2486.2006.01288.x.

463 Didiano TJ, Turley NE, Everwand G, Schaefer H, Crawley MJ, Johnson MTJ. 2014.

464 Experimental test of plant defence evolution in four species using long-term rabbit 465 exclosures. Journal of Ecology 102:584-594. DOI: 10.1111/1365-2745.12227.

466 Doyle JJ, Doyle JL. 1987. A rapid DNA isolation procedure for small quantities of fresh leaf 467 tissue. Phytochem. Bull. 74:11-15.

Dray S, Dufour A-B. 2015. The ade4 Package: Implementing the Duality Diagram for Ecologists . Journal of Statistical Software 22. DOI: 10.18637/jss.v022.i04. 
engineering by large grazers enhances carbon stocks in a tidal salt marsh. Marine Ecology

472 Progress Series 537:9-21. DOI: 10.3354/meps11447.

473 Evans SM, Sinclair EA, Poore AGB, Bain KF, Vergés A. 2016. Genotypic richness predicts

474 phenotypic variation in an endangered clonal plant. PeerJ 2016:1-24. DOI:

$475 \quad 10.7717$ peerj.1633.

476 Evju M, Austrheim G, Halvorsen R, Mysterud A. 2009. Grazing responses in herbs in relation to 477 herbivore selectivity and plant traits in an alpine ecosystem. Oecologia 161:77-85. DOI: $478 \quad 10.1007 / \mathrm{s} 00442-009-1358-1$.

479 Fokkema W, de Boer W, van der Jeugd HP, Dokter A, Nolet BA, De Kok LJ, Elzenga JTM, Olff 480 H. 2016. The nature of plant adaptations to salinity stress has trophic consequences. Oikos $481 \quad$ 125:804-811. DOI: 10.1111/oik.02757.

482 Funk JL, Larson JE, Ames GM, Butterfield BJ, Cavender-Bares J, Firn J, Laughlin DC, Sutton483 Grier AE, Williams L, Wright J. 2017. Revisiting the Holy Grail: Using plant functional 484 traits to understand ecological processes. Biological Reviews 92:1156-1173. DOI: $485 \quad 10.1111 /$ brv.12275.

486 Givnish TJ. 2002. Ecological constraints on the evolution of plasticity in plants. Evolutionary 487 Ecology 16:213-242. DOI: 10.1023/A:1019676410041.

488 He Q, Silliman BR. 2016. Consumer control as a common driver of coastal vegetation 489 worldwide. Ecological Monographs 86:278-294. DOI: 10.1002/ecm.1283. variation of grass and forb species in German meadows and pastures. Journal of Vegetation 
493 Jarne P, Lagoda PJL. 1996. Microsatellites, from molecules to populations and back. Trends in 494 Ecology and Evolution 11:424-429. DOI: 10.1016/0169-5347(96)10049-5.

495 Jessen MT, Kaarlejärvi E, Olofsson J, Eskelinen A. 2020. Mammalian herbivory shapes

496 intraspecific trait responses to warmer climate and nutrient enrichment. Global Change

497 Biology 26:6742-6752. DOI: 10.1111/gcb.15378.

498 Kahmen S, Poschlod P. 2008. Effects of grassland management on plant functional trait

499 composition. Agriculture, Ecosystems and Environment 128:137-145. DOI:

$500 \quad$ 10.1016/j.agee.2008.05.016.

501 Kleijn D, Steinger T. 2002. Contrasting effects of grazing and hay cutting on the spatial and 502 genetic population structure of Veratrum album, an unpalatable, long-lived, clonal plant 503 species. Journal of Ecology 90:360-370.

504 Kolliker R, Stadelmann, F J, Reidy B, Nosberger J. 1998. Fertilization and defoliation frequency 505 affect genetic diversity of Festuca pratensis Huds. in permanent grasslands. Molecular $506 \quad$ Ecology:1557-1567.

507 Kotanen PM, Bergelson J. 2000. Effects of simulated grazing on different genotypes of

508 Bouteloua gracilis: How important is morphology? Oecologia 123:66-74. DOI:

$509 \quad 10.1007 / \mathrm{s} 004420050990$.

510 Kuijper DPJ, Bakker JP. 2005. Top-down control of small herbivores on salt-marsh vegetation 511 along a prouctivity gradient. Ecology 86:914-923.

512 Kuijper DPJ, Bakker JP. 2008. Unpreferred plants affect patch choice and spatial distribution of 
513 European brown hares. Acta Oecologica 34:339-344. DOI: 10.1016/j.actao.2008.06.007.

514 Lecerf A, Chauvet E. 2008. Intraspecific variability in leaf traits strongly affects alder leaf

515 decomposition in a stream. Basic and Applied Ecology 9:598-605. DOI:

$516 \quad$ 10.1016/j.baae.2007.11.003.

517 Lindsay A, Clark V, Clark ML V. 2018. Package ‘ polysat .’ DOI: 10.1111/1755-

$518 \quad$ 0998.12639>.License.

519 Louault F, Pillar VD, Aufrère J, Garnier E, Soussana J. 2005. Plant Traits and Functional Types

520 in Response to Reduced Disturbance in a Semi-Natural Grassland. Journal of Vegetation

$521 \quad$ Science 16:151-160.

522 Menu S, Gauthier G, Reed A. 2002. Changes in survival rates and population dynamics of 523 greater snow geese over a 30 year period. Journal of Applied Ecology 39:91-102.

524 Merilä J, Hendry AP. 2014. Climate change, adaptation, and phenotypic plasticity: The problem 525 and the evidence. Evolutionary Applications 7:1-14. DOI: 10.1111/eva.12137.

526 Nolte S, Wanner A, Stock M, Jensen K. 2019. Elymus athericus encroachment in Wadden Sea

527 salt marshes is driven by surface elevation change. Applied Vegetation Science 22:454-464.

528 DOI: $10.1111 /$ avsc. 12443.

529 Olff H, Leeuw J De, Bakker JP, Platerink RJ, van Wijnen HJ. 1997. Vegetation Succession and

$530 \quad$ Herbivory in a Salt Marsh: Changes Induced by Sea Level Rise and Silt Deposition Along 531 an Elevational Gradient. Journal of Ecology 85:799. DOI: 10.2307/2960603.

532 Olff H, Ritchie ME. 1998. Effects of herbivores on grassland plant diversity. Trends in Ecology 533 and Evolution 13:261-265. DOI: 10.1016/S0169-5347(98)01364-0. 
534 Olofsson J, Hulme philip E, Oksanen L, Suominen O. 2004. Importance of large and small

535 mammalian herbivores for the plant community structure in the forest tundra ecotone. Oikos 536 106:324-334. DOI: 10.3923/biotech.2011.136.148.

537 Pérez-Harguindeguy N, Díaz S, Garnier E, Lavorel S, Poorter H, Jaureguiberry P, Bret-Harte 538 MS, Cornwell WK, Craine JM, Gurvich DE, Urcelay C, Veneklaas EJ, Reich PB, Poorter L, 539 Wright IJ, Ray P, Enrico L, Pausas JG, de Vos AC, Buchmann N, Funes G, Quétier F, 540 Hodgson JG, Thompson K, Morgan HD, ter Steege H, Sack L, Blonder B, Poschlod P, 541 Vaieretti M V, Conti G, Staver AC, Aquino S, Cornelissen JHC. 2016. Corrigendum to: 542 New handbook for standardised measurement of plant functional traits worldwide. $543 \quad$ Australian Journal of Botany 64:715. DOI: 10.1071/bt12225_co.

544 R Core Team. (2020). R: A language and environment for statistical comput- ing. R Foundation 545 for Statistical Computing.

546 Rico Y, Wagner HH. 2016. Reduced fine-scale spatial genetic structure in grazed populations of 547 Dianthus carthusianorum. Heredity 117:367-374. DOI: 10.1038/hdy.2016.45.

548 Röder MS, Korzun V, Wendehake K, Plaschke J, Tixier MH, Leroy P, Ganal MW. 1998. A 549 microsatellite map of wheat. Genetics 149:2007-2023. DOI: 10.1007/bf00279889. Software 48:1-93.

Ruifrok JL, Postma F, Olff H, Smit C. 2014. Scale-dependent effects of grazing and topographic 553 heterogeneity on plant species richness in a Dutch salt marsh ecosystem. Applied Vegetation

$554 \quad$ Science 17:615-624. DOI: 10.1111/avsc.12107. 
555 Schrama M, Berg MP, Olff H. 2012. Ecosystem assembly rules: The interplay of green and

556 brown webs during salt marsh succession. DOI: 10.1890/11-1102.1.

557 Schrama M, Kuijper DPJ, Veeneklaas RM, Bakker JP. 2015. Long-term decline in a salt marsh

558 hare population largely driven by bottom-up factors. Ecoscience 22:71-82. DOI:

$559 \quad 10.1080 / 11956860.2015 .1079409$.

560 Schrama M, van der Plas F, Berg MP, Olff H. 2017. Decoupled diversity dynamics in green and

561 brown webs during primary succession in a saltmarsh. Journal of Animal Ecology 86:158-

562 169. DOI: $10.1111 / 1365-2656.12602$.

563

564

565

566

567

568

569

570

571

572

573

574

575

576

Siefert A, Violle C, Chalmandrier L, Albert CH, Taudiere A, Fajardo A, Aarssen LW, Baraloto C, Carlucci MB, Cianciaruso M V., de L. Dantas V, de Bello F, Duarte LDS, Fonseca CR, Freschet GT, Gaucherand S, Gross N, Hikosaka K, Jackson B, Jung V, Kamiyama C, Katabuchi M, Kembel SW, Kichenin E, Kraft NJB, Lagerström A, Bagousse-Pinguet Y Le, Li Y, Mason N, Messier J, Nakashizuka T, Overton JM, Peltzer DA, Pérez-Ramos IM, Pillar VD, Prentice HC, Richardson S, Sasaki T, Schamp BS, Schöb C, Shipley B, Sundqvist M, Sykes MT, Vandewalle M, Wardle DA. 2015. A global meta-analysis of the relative extent of intraspecific trait variation in plant communities. Ecology Letters 18:1406-1419. DOI: 10.1111/ele.12508.

Smith RK, Jennings N V., Harris S. 2005. A quantitative analysis of the abundance and demography of European hares Lepus europaeus in relation to habitat type, .... Mammal Review 35:1-24. DOI: 10.1111/j.1365-2907.2005.00057.x.

Sun G-LL, Salomon B, Bothmer R V. 1998. Characterization and analysis of microsatellite loci in Elymus caninus (Triticeae: Poaceae). Theoretical and Applied Genetics 96:676-682. 
DOI: $10.1007 / \mathrm{s} 001220050788$.

578 Valladares F, Gianoli E, Gomez JM. 2007. Ecological limits to plant phenotypic plasticity. New

579 Phytologist 176:749-763. DOI: 10.1111/j.1469-8137.2007.02275.x.

580 Van Der Graaf AJ, Stahl J, Bakker JP. 2005. Compensatory growth of Festuca rubra after

581 grazing: Can migratory herbivores increase their own harvest during staging? Functional

582 Ecology 19:961-969. DOI: 10.1111/j.1365-2435.2005.01056.x.Van de Koppel J, Huisman

583 J, Van Der Wal R, Olff H. 1996. Patterns of Herbivory Along a Prouductivity Gradient : An

584 Empirical and Theoretical Investigation. Ecology 77:736-745. DOI: 10.2307/2265498.

585 Veeneklaas R, Bockelmann A, Reusch T, Bakker J. 2011. Effect of grazing and mowing on the

586 clonal structure of Elytrigia atherica: A long-term study of abandoned and managed sites.

$587 \quad$ Preslia $83: 455-470$.

588 Vieira MLC, Santini L, Diniz AL, Munhoz C de F. 2016. Microsatellite markers: What they

589 mean and why they are so useful. Genetics and Molecular Biology 39:312-328. DOI:

$590 \quad 10.1590 / 1678-4685-G M B-2016-0027$.

591 Violle C, Enquist BJ, McGill BJ, Jiang L, Albert CH, Hulshof C, Jung V, Messier J. 2012. The

592 return of the variance: Intraspecific variability in community ecology. Trends in Ecology

593 and Evolution 27:244-252. DOI: 10.1016/j.tree.2011.11.014.

594 Wal R Van Der, Lieshout S Van, Bos D, Drent RH. 2000. Are Spring Staging Brent Geese

595 Evicted by Vegetation Succession? Ecography 23:60-69.

596 Van Der Wal R, Kunst P, Drent R. 1998. Interactions between hare and brent goose in a salt

597 marsh system: Evidence for food competition? Oecologia 117:227-234. DOI: 
599 Van Der Wal R, Wijnen H van, Wieren S van, Beucher O, Bos D. 2000. On Facilitation between

600 Herbivores: How Brent Geese Profit from Brown Hares. Ecology 81:969-980.

601 Westerband AC, Funk JL, Barton KE. 2021. Intraspecific trait variation in plants: a renewed

602 focus on its role in ecological processes. Annals of Botany:397-410. DOI:

$603 \quad 10.1093 / \mathrm{aob} / \mathrm{mcab} 011$.

604 Westneat DF, Potts LJ, Sasser KL, Shaffer JD. 2019. Causes and Consequences of Phenotypic

605 Plasticity in Complex Environments. Trends in Ecology and Evolution 34:555-568. DOI:

$606 \quad$ 10.1016/j.tree.2019.02.010.

607 Whitlock R, Grime JP, Burke T. 2010. Genetic vaiation in plant morpholoy contributes to the

608 species-level structure of grassland communities. Ecology 91:1344-1354.

609 Wijnen HJ Van, Wal R Van Der, Bakker JP. 1999. The Impact of Herbivores on Nitrogen

610 Mineralization Rate : Consequences for Salt-Marsh Succession. Oecologia 118:225-231.

611 


\section{Figure 1}

Sampling location and scheme

Location for the 22-year exclosures at the early and intermediate successional stage in the saltmarsh of the island of Schiermonnikoog. Pictures of the exclosures at the early and intermediate successional stages are shown. Sampling plots $(1 \times 1 \mathrm{~m})$ within an exclosure and sampling scheme for individuals of Elytrigia atherica within a $1 \times 1 \mathrm{~m}$ plot are shown. We followed the same sampling scheme for each plot. Elytrigia atherica did not always occur within each grid, thus sample size varied for each plot. Sampling plots and scheme were similar outside the exclosures (in the grazed area) at both successional stages. Number of hares and geese indicate the abundance of small herbivores such that the early successional stage had higher grazing pressure (indicated by two hares and two geese) relative to the intermediate successional stage (indicated by one hare and one goose). Note, only the map of the saltmarsh, but not exclosures and sampling plots, is projected according to its actual size. 

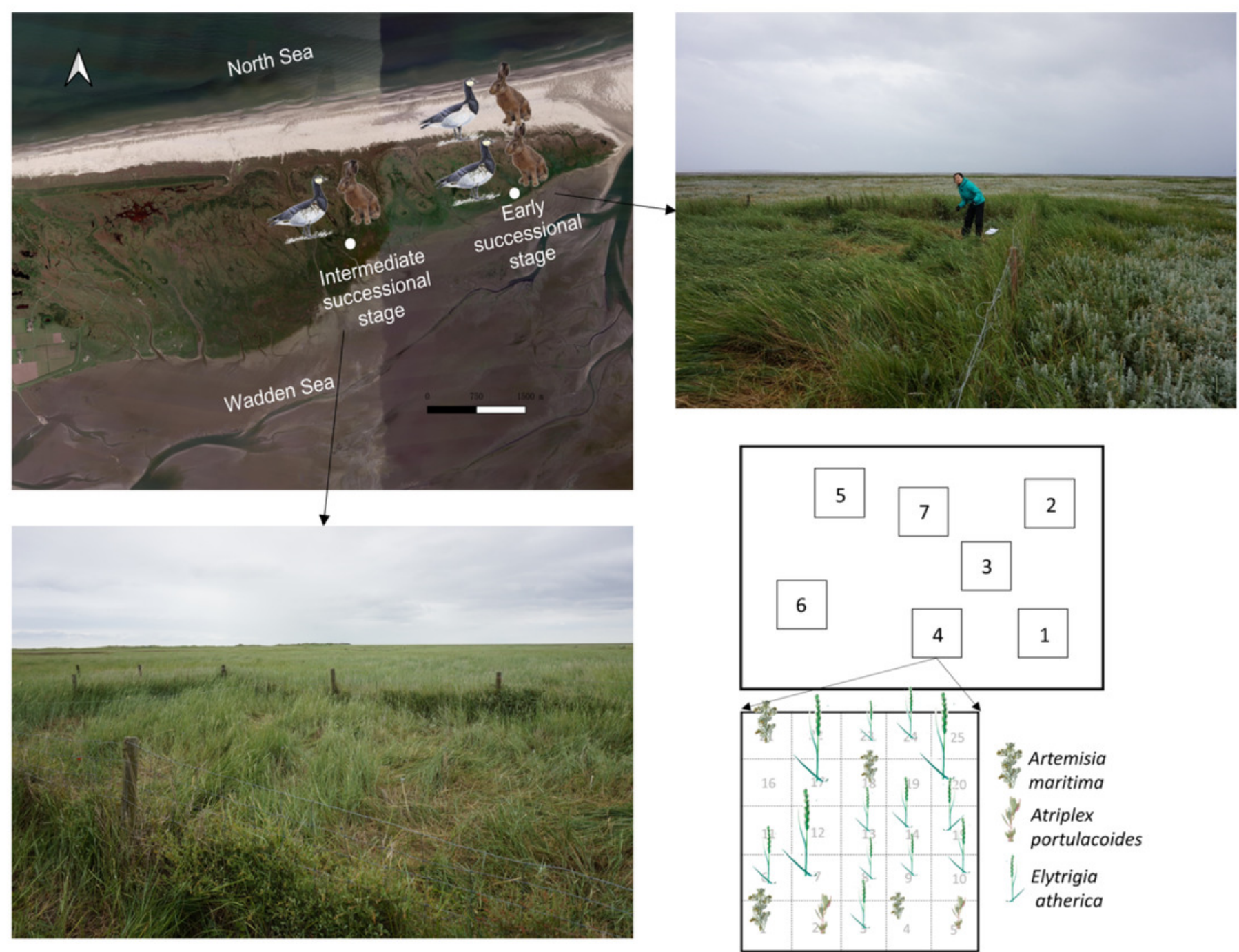


\section{Figure 2}

Means and variations in functional traits of individual stems of Elytrigia atherica in the grazed and ungrazed plots at the early and intermediate stages.

Traits include height $(\mathrm{cm})$, aboveground biomass $(\mathrm{g})$, flower frequency. Results for specific leaf area $\left(\mathrm{cm}^{2} \mathrm{~g}^{-1}\right)$ and leaf dry matter content $\left(\mathrm{g} \mathrm{g}^{-1}\right)$ are not shown because small herbivores generally did not impact mean and ITV in these two traits at both successional stages. Dots are the means, error bars show 1 se. Asterisks indicate significant levels: $* \mathrm{P}<0.1 ; * * \mathrm{P}<0.05$; *** $\mathrm{P}<0.001$. See Table S3 for test statistics.

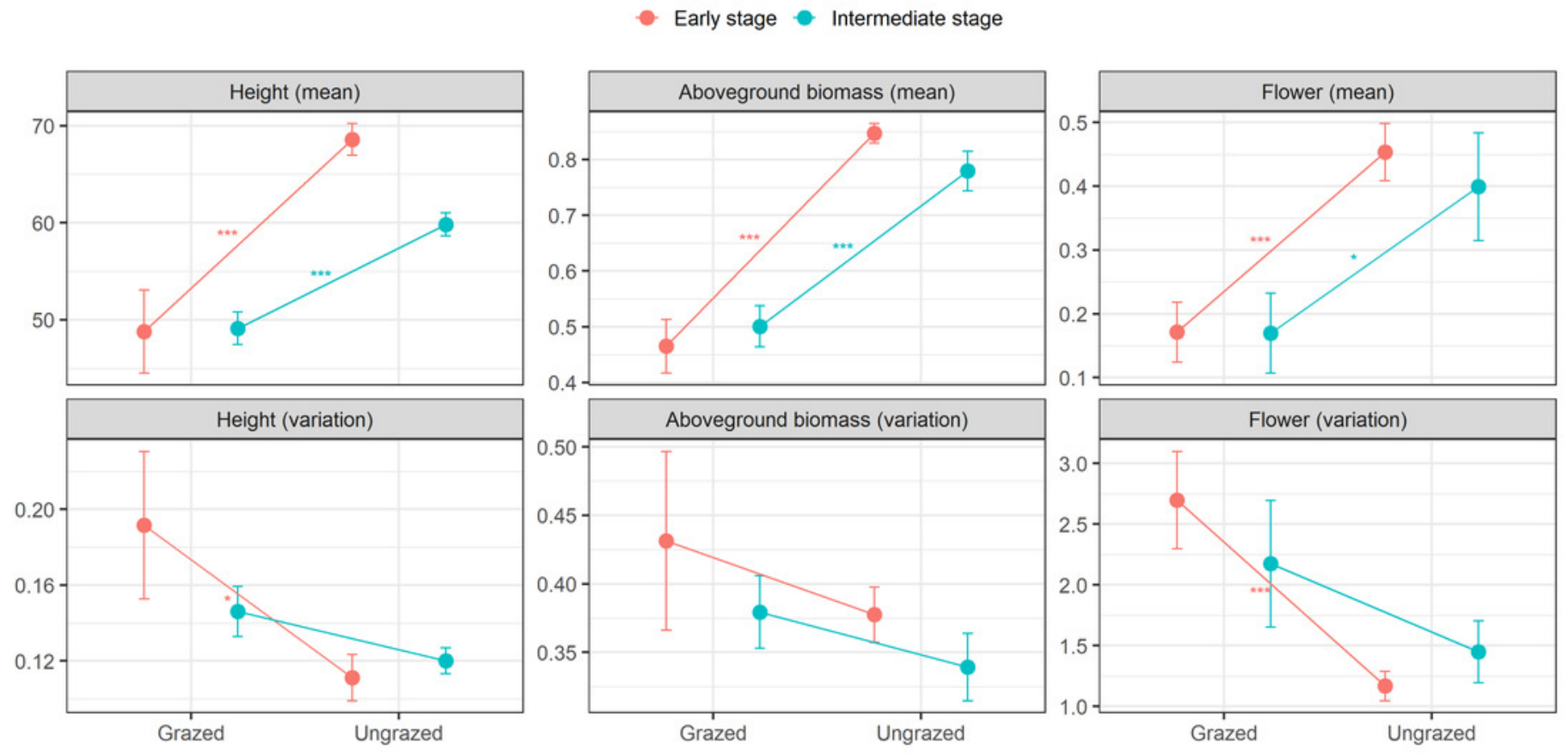




\section{Figure 3}

Intraspecific trait variation (ITV) of the dominant grass Elytrigia atherica and the direct and indirect effects of small herbivores on ITV in local communities at the early (A-C) and intermediate stage (D-F).

The direct effects, indirect effects through genotypes, indirect effects through abiotic variations, and total effects of small herbivores on ITV in each trait are summarized in Table 1. Model fit the data well (for all models at the early successional stage: $\chi^{2}=4.409, \mathrm{df}=3, \mathrm{~N}$ $=14, p>0.05$; for all models at the intermediate successional stage: $\chi^{2}=6.559, \mathrm{df}=6, \mathrm{~N}=$ $14, p>0.05)$. Variance explained for clay thickness (variation), topographic variation, and genotypic richness for models at the early successional stage are $0.024,0.008$, and 0.056 , respectively. Variance explained for clay thickness (variation), topographic variation, genotypic richness, and genotype diversity for models at the intermediate successional stage are $0.079,0.045,0.016$, and 0.289 , respectively. Number of hares and geese indicate the abundance of small herbivores such that the early successional stage had higher grazing pressure (indicated by two hares and two geese) relative to the intermediate stage (indicated by one hare and one goose). Boxes are measured variables. Arrows denote unidirectional relationships among variables. Blue arrows are significant positive relationships, red arrows are significant negative relationships, and grey arrows show non-significant relationships. The width of the arrows indicates the strength of the pathways. The values on the arrows denote standardized path coefficients. Asterisks indicate significant paths: $* p<0.1 ;{ }^{* *} p<$ 0.05 ; ${ }^{* * *} p<0.001$. See Fig. S2 for the direct and indirect effects of small herbivores on ITV in specific leaf area at the both successional stages. Note that leaf dry matter content was not evaluated in structural equation models due to limited sample size (see online supporting text). 


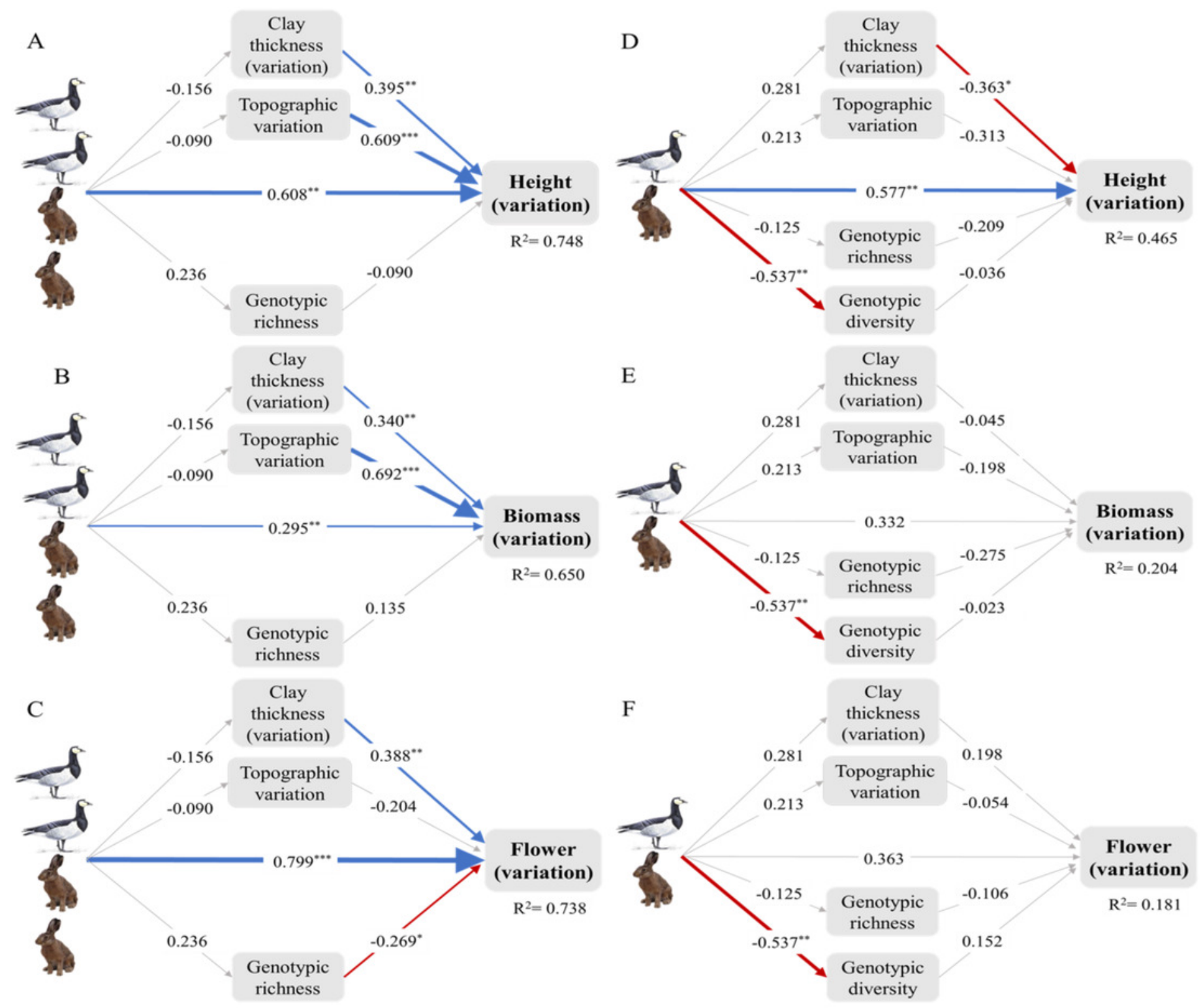




\section{Table $\mathbf{1}$ (on next page)}

Direct and indirect effects of hares and geese on intraspecific trait variation (ITV) of Elytrigia atherica at the early and intermediate successional stages.

See online supporting text for an example of how these data were calculated and how significance was determined using lavaan SEM. Asterisks indicate significant effects: $* p<$ $0.1 ; * *<0.05 ; * * * p<0.001$. 
1

\begin{tabular}{cccccc}
\hline $\begin{array}{c}\text { Successional } \\
\text { stages }\end{array}$ & Traits & $\begin{array}{c}\text { Direct } \\
\text { effects }\end{array}$ & $\begin{array}{c}\text { Indirect effects } \\
\text { through } \\
\text { genotypes }\end{array}$ & $\begin{array}{c}\text { Indirect effects } \\
\text { through abiotic } \\
\text { variations }\end{array}$ & $\begin{array}{c}\text { Total } \\
\text { effects }\end{array}$ \\
\hline \multirow{2}{*}{ Early } & Height & $0.608^{* * *}$ & -0.021 & -0.117 & $0.47^{* *}$ \\
& Biomass & $0.295^{* *}$ & 0.032 & -0.116 & 0.211 \\
& Flowering & $0.799^{* * *}$ & -0.063 & -0.042 & $0.694^{* * *}$ \\
& & & & & \\
Intermediate & Height & $0.577^{* *}$ & 0.045 & -0.169 & $0.454^{*}$ \\
& Biomass & 0.332 & 0.022 & -0.055 & 0.299 \\
& Flowering & 0.363 & -0.068 & 0.044 & 0.339 \\
\hline
\end{tabular}

2 